\title{
Trabalho infantil doméstico: perfil bio-sócio- econômico e configuração da atividade no município de João Pessoa, PB
}

\author{
Maria de Fátima Pereira Alberto ${ }^{1}$, Denise Pereira dos Santos, Fernanda Moreira Leite, José \\ Wilson de Lima, Gláucia Pereira da Paixão e Sebastião Alves da Silva \\ Universidade Federal da Paraíba
}

\begin{abstract}
O trabalho versa sobre uma pesquisa com que se buscou caracterizar a atividade do trabalho infantil doméstico no município de João Pessoa, Paraíba, a partir de crianças e adolescentes estudantes de escolas públicas municipais e estaduais. Participaram da pesquisa 100 sujeitos de ambos os sexos, na faixa compreendida entre 7 e 18 anos de idade. Utilizaram-se dois instrumentos: o primeiro identificava se a criança ou o adolescente eram trabalhadores e o segundo era um questionário composto de questões abertas e fechadas, que contemplavam, entre outros, aspectos como perfil sócio-econômico e atividade. Para a análise, utilizou-se a estatística descritiva e o software SPSS. Os resultados revelaram que 34\% estavam na faixa entre 10 e 14 anos e $25 \%$, entre 15 e 16 anos. Constatou-se um recorte de gênero (73\% eram meninas), raça/etnia (67\% eram afrodescendentes) e classe social (para 37\% a renda da família era de um quarto do salário mínimo). 30\% trabalhavam em mais de um turno e exerciam de 9 a 15 horas de trabalho diário. Os sujeitos realizavam tarefas de cuidado da casa, seguidas do cuidado com pessoas. A atividade configurou-se como exploradora, naturalizada, invisível e ainda exigia esforço físico e roubava o tempo do ócio necessário ao desenvolvimento.
\end{abstract}

Palavras-chave: Trabalho infantil, Trabalho doméstico, Atividade.

Domestic child labour: bio-socio-economic profile and configuration of the activity in the city of João Pessoa, Brazil

The paper reports on a research that aimed to characterize the activity of domestic child labour, in the city of João Pessoa, Brazil, with child and adolescents who study in municipal and state public school. The research had the participation of 100 subjects from both sexes, with ages between 7 and 18 years old. It used two instruments: the first identified if the child or the adolescent were workers, and the second was a questionnaire composed by open and closed questions, that contemplate, among others, aspects like socio-economic profile and activity. To analyze data, it was used descriptive statistics and the software SPSS. Results reveal that $34 \%$ were between 10 and 14 years old, and $25 \%$ between 15 and 16 years old. It was verified in concerning of gender ( $73 \%$ are girls), race/ethnicity $(67 \%$ are afro-descendant) and social class (to 37\%, familiar income was a quarter of minimum wage). 30\% worked in shift, exercise from 9 to 15 work hours per day. They make domestic work, followed by taking care of people. The activity was configured as exploiter, naturalized, and invisible, and still demanded physical effort and stole leisure necessary to development.

Keywords: Child labour, Domestic labour, Activity.

\section{Introdução}

$\mathrm{E}_{\mathrm{i}}^{\mathrm{s}}$ te artigo versa sobre uma pesquisa que objetivou caracterizar a atividade do trabalho infantil doméstico (doravante chamado TID) no município de João Pessoa, Paraíba, através dos educandos da escola pública municipal e estadual. Os dados revelaram a naturalização dessa realidade, o perfil bio-sócio-econômico dos trabalhadores e trabalhadoras, a configuração da atividade (socialização, ajuda e remuneração), o caráter explorador e invisível que fere os direitos de crianças e adolescentes.

1 Doutora em Sociologia pela Universidade Federal de Pernambuco. Professora do Departamento de Psicologia e do Programa de Pós-Graduação em Psicologia Social da UFPB. Pesquisadora integrante do Grupo Pesquisa Subjetividade e Trabalho (GPST) da UFPB. Líder do Núcleo de Pesquisa sobre o Desenvolvimento da Infância e Adolescência em Situação de Risco Pessoal e Social da UFPB. 
No Brasil, em 2003, segundo o Instituto Brasileiro de Geografia e Estatística (2004), existiam 5,1 milhões de crianças e adolescentes trabalhadores entre 5 e 17 anos de idade. Especificamente no trabalho infantil doméstico, foi constatada no país, em 2005, a existência de 400 mil crianças e adolescentes exercendo essa atividade (Agência de Notícias dos Direitos da Infância, 2005). Na Paraíba, não existiam dados precisos que retratassem a amplitude e as características dessa atividade junto a crianças e adolescentes.

O Nordeste, em 2003, concentrava cerca de $42 \%$ do total de crianças e adolescentes trabalhadores no país, sendo que, desses, 33,5\% tinham entre 5 e 13 anos de idade. A Paraíba, nesse mesmo ano, era o estado que possuía a maior proporção de crianças e adolescentes trabalhadores, em comparação com os outros estados da região, com cerca de 39,4\% (Instituto Brasileiro de Geografia e Estatística, 2004). Tal situação, de extrema desigualdade, retrata a entrada precoce de milhares de crianças e adolescentes no trabalho, em busca de renda que possibilite sua sobrevivência e a de sua família.

As referências existentes acerca da temática apontam que o trabalho infantil doméstico está intimamente ligado às discriminações de gênero, de raça/etnia, de classe social e de pobreza (Rizzini \& Fonseca, 2002; Sabóia, 2000; Santana \& Almeida Filho, 1994; Tavares, 2002). Indicam também que o TID tem implicações na construção da identidade social (Santana \& Newman, 2001), do processo de escolarização, da construção das perspectivas de futuro e é, principalmente, uma violação de direitos humanos (Alberto, Nunes, Cavalcante \& Santos, 2005; Sabóia, 2000; Tavares, 2002).

O trabalho infantil doméstico, da mesma forma que o trabalho doméstico em geral, é uma atividade perpassada pela questão de gênero em que as pessoas do sexo feminino preponderam, em seu desempenho, em relação às pessoas do sexo masculino (Alberto et al., 2005; Mendes, 2004; Moreira \& Stengel, 2003; Tavares, 2002). De acordo com a PNAD (2001), os casos de emprego doméstico exercido por mulheres chegam a 94,5\% do total (Instituto Brasileiro de Geografia e Estatística, 2002). Rizzini e Fonseca (2002) apontam, em seu estudo sobre as práticas culturais que permeiam o trabalho doméstico, que, historicamente, dentro de uma cultura patriarcal, aos homens cabia a tarefa de dar provisão à família e às mulheres delegavam-se as tarefas de cuidado da casa e dos filhos. Com esse fim, sua iniciação ocorria desde cedo, ainda criança, como preparação para execução dessas tarefas em sua futura casa.

Dejours (1999) afirma que as tarefas exercidas nesse tipo de trabalho são vistas como inerentes ao "ser mulher", ou seja, ao feminino, revelando um processo de naturalização. A partir daí, decorre que as habilidades exigidas para a execução do trabalho doméstico sejam desconsideradas enquanto competências adquiridas e, por conseguinte, não sejam reconhecidas como de valor. Isso faz com que as trabalhadoras domésticas recebam baixa remuneração, além de sofrerem exploração, sem limites de jornada. Abramo (2004), Hirata (1998) e Kergoat (1986) corroboram o raciocínio do referido autor ao apontarem que a questão cultural do papel atribuído ao sexo feminino persiste, mesmo com o fato de as mulheres já haverem atingido um nível médio de escolaridade superior ao dos homens, remetendo-as a profissões ligadas ao cuidado, entre as quais, o trabalho doméstico. Whitaker (2002), em estudo realizado em assentamentos no Estado de São Paulo, ressalta que, naquele contexto, o processo de socialização que ocorria com as meninas as preparava para o futuro papel de esposas e mães, reduzindo o tempo das brincadeiras, do estudo fora da escola e causando uma limitação das suas atividades ao espaço do lar.

Outra via de análise é a questão de raça/etnia ${ }^{2}$. O corpo teórico existente acerca do tema (Alberto et al., 2005; Haas, 2003; Mendes, 2004; Peres, 2002; Tavares, 2002) mostra que

2 Diante das controvérsias nas discussões dessa temática, quanto a uma definição do que seja raça e do que seja etnia, preferiu-se, então, utilizar-se, aqui, a expressão raça/etnia. Ainda que se considere que essa discussão inclua diversos aspectos culturais e históricos, o termo refere-se, aqui, principalmente a questões ligadas à cor da pele. 
o trabalho infantil doméstico é exercido em sua grande maioria por afrodescendentes, categoria que é compreendida por negros, pardos, mulatos e morenos. Na época da escravidão (particularmente nos estados do Nordeste devido ao ciclo da cana-de-açúcar), para as crianças negras, "aprender a trabalhar significava sobretudo aprender a obedecer e servir ao senhor" (Organização Internacional do Trabalho, 2001, p. 26). Isto é, trabalhar era sinônimo também de aprender a ser escravo. Essa herança histórica fez com que, mesmo após o fim da escravidão, as atividades que exigissem menor qualificação sempre fossem reservadas às pessoas negras e a seus descendentes ou a pessoas brancas pobres.

No caso das meninas negras, ser escrava era servir de mucamas, as domésticas daquele tempo. Posteriormente, as mulheres e meninas negras passaram de mucamas a uma nova categoria, as criadas, servas ou domésticas, que ofereciam sua força de trabalho em troca de casa e comida ou por baixas remunerações, principalmente as que possuíam pouca qualificação ou eram descendentes diretas de escravos. Reforçou-se, assim, o ciclo da falta de qualificação e da discriminação racial, que leva à pobreza, que, por si só, tende a perpetuar aquela primeira (Kowarick, 1994).

Aliada às questões de gênero e raça/etnia, tem-se também no TID uma questão de classe social. Essa é uma categoria importante de análise, uma vez que a maioria das crianças e dos adolescentes que exercem TID provém das classes populares. Por classes populares, considera-se um coletivo socialmente heterogêneo, cuja unidade não se dá em termos de sistema de produção, mas em termos políticos, constituído-se em uma aliança social e política. Ou seja, a heterogeneidade dos trabalhadores dá-se no interior de uma classe, unida por interesses políticos e por sua posição social, e não no sistema de produção, como no conceito clássico de classe operária ou de classe trabalhadora. A classe trabalhadora brasileira (formada por migrantes nordestinos e europeus, com interesses diversos) não constituía, aos olhos dos intelectuais, uma "classe em si" e "para si". Na opinião deles, esse aglomerado heterogêneo vai marcar a constituição de vários movimentos organizados de manifestação em defesa de direitos sociais e de cidadania. É assim que se constituem as classes populares. Embora ela não tenha o mesmo substrato econômico, tem, no político, o elo de ligação que marchará, a partir do urbano, para confrontar-se com as classes dominantes, tendo o Estado como alvo das suas reivindicações (Moisés, 1982).

O trabalho infantil doméstico tem um caráter de invisibilidade que o descaracteriza como um trabalho, uma vez que o naturaliza ao universo do espaço privado do lar, escondendo suas implicações (Mendes, 2004; Rizzini \& Fonseca, 2002; Tavares, 2002). A invisibilidade decorre de vários fatores: ou porque é executado no lar, muitas vezes nomeado como ajuda, outras vezes porque é concebido como forma de aprendizagem das tarefas de reprodução ou de participação e contribuição dos membros de uma família. Apesar de despender muito tempo e apresentar muitas demandas físicas e psíquicas, não é reconhecido enquanto trabalho, por invalidar socialmente as exigências que a atividade requer. A articulação desses vários aspectos e a concepção histórica que norteou essa atividade de trabalho doméstico no Brasil (da senzala à criadagem) são fenômenos explicativos do conceito social de menor valor de que padecem tanto as atividades feitas pelos adultos, quanto aquelas feitas por crianças e adolescentes.

Segundo Moreira e Stengel (2003), o trabalho doméstico tem um caráter de invisibilidade que pode afetar a auto-estima e a construção da identidade de crianças e adolescentes. O trabalho infantil e doméstico, em particular pela humilhação, pela baixa autoestima e pela descaracterização como trabalhador, poderá promover o embotamento afetivo. Da imagem de si emergirá ou não uma estima de si, como o amor próprio, influenciada pela maneira de imaginar-se como será visto pelos outros. A imagem de si depende da complacência dessas relações interpessoais, do aval social para consubstanciar-se, de modo que a imagem de si é um reflexo desse jogo de inter-relações (Alberto, 2002; Alberto et al., 2005). Além do que a carga de trabalho, as exigências físicas e psíquicas fazem com que o trabalho doméstico 
exproprie as crianças e adolescentes do tempo de ócio, próprio e necessário ao brincar e ao desenvolvimento (Alberto et al., 2005; Heilborn, 2000; Tavares, 2002).

Associados a esses aspectos, juntam-se outros como a naturalização do trabalho infantil como um antídoto contra a marginalidade. Vários autores versaram sobre isso, dentre os quais citem-se Heilborn (2000), Mendes (2004), Organização Internacional do Trabalho (2001). É comum a autores a concepção de que, no Brasil, o trabalho infantil contempla uma dimensão ideológica: a inserção de crianças e adolescentes das classes populares no trabalho. Essa é uma forma de disciplinamento, de adestramento, da qual fazem uso as classes dominantes que, sob formas variadas, as conduzem ao trabalho. São formas sutis e dispersas de relações de poder, como, por exemplo, incutir em meninos e meninas, desde cedo, a domesticação do corpo e da mente para o trabalho, além da introjeção do trabalho como elemento formador ou, ainda, como um antídoto para a marginalidade. Assim, o sistema político de dominação transforma o corpo, com a disciplina e com a da força do trabalho. Uma vez que a pobreza era tida como perigosa pelas classes dominantes, o disciplinamento via trabalho, historicamente, sempre foi visto como única alternativa para tornar crianças e adolescentes pobres em sujeitos úteis para a sociedade. Com isso, reforça-se a ideologia do trabalho como formador, ocultando-se o direito à formação via instituições como a escola. Essa concepção ainda permanece, apesar do advento da visão das crianças e adolescentes como sujeitos de direitos a partir da Constituição Federal de 1988 e do Estatuto da Criança e do Adolescente.

Ainda que, por um lado, o trabalho infantil doméstico tenha se configurado enquanto atividade que discrimina crianças e adolescentes que o executam, por questões de raça/etnia, de gênero ou de classe social - e seja justificado por diferentes expedientes de caráter ideológico -, por outro, houve toda uma construção social desses mesmos sujeitos enquanto detentores de direitos. Esse fato é de extrema importância, uma vez que embasa uma série de movimentos em prol da defesa e da efetivação desses direitos, principalmente do direito a usufruir das condições necessárias ao seu desenvolvimento, incluída a proibição da execução de trabalhos perigosos ou que os exponham a riscos. Vários documentos de direitos humanos, nacionais e internacionais, versam sobre a garantia de direitos e sobre a proibição do trabalho infantil. $^{3}$

A luta pelos direitos das crianças e adolescentes passa diretamente pela construção da noção de infância e de adolescência, que, de acordo com Ariès (1981), foi historicamente construída. A crianças era vista, até o século XVII, apenas como um adulto "menos capaz", sem maiores considerações acerca do seu desenvolvimento e sem investimento intenso de amor, de carinho e de cuidados por parte dos pais e de outros adultos. Assim, o conceito atual de infância surge no século XVIII, quando se inicia uma nítida separação entre a criança e o adulto. A família passou a ser o núcleo por excelência, responsável pelo cuidado e educação das crianças, e, para tal, privatizou-se no espaço do lar e em relação à vida pública em nome de um cuidado que deveria ser devotado às crianças (Ariès, 1981).

Mas, apesar de conquistar um espaço como período de desenvolvimento durante o qual ela deva ser preparada a partir de determinadas condições necessárias à vida adulta, vê-se que a definição de infância está condicionada à sua situação de classe social. Apenas aos filhos das classes média e alta é garantido o direito de desfrutar do tempo de brincadeiras, do estudo e da formação. Há uma outra infância, ou melhor, há outros sujeitos a quem essas condições são negadas: filhos do proletariado e sub-proletariado, a infância trabalhadora (Marx, 1968) ou a infância das classes populares.

Nesse sentido, compartilha-se da ideia de Pilotti (1995), que afirma: “(...) a análise da posição ocupada pela infância na estrutura social requer o desenvolvimento de categorias

3 Entre eles, citem-se a Constituição Federal, nos Artigos 5ำ 6o, 203, 205, 208 e 227; o Estatuto da Criança e do Adolescente (ECA), Artigos 3ำ 4ำ 5ำ 53, 54, 60, 61, 65, 67 68, 69, 70. No plano internacional, citem-se a Declaração Universal dos Direitos da Criança, a Convenção Internacional dos Direitos da Criança, nos Artigos 3ㅜ 4으, 5o , 27, 28, 31, 32; as Convenções da Organização Internacional do Trabalho (OIT), de no 138 e 180, e as Recomendações no 146 e 190. 
analíticas específicas" (pp. 25-28). Partindo dessa visão, o autor diferencia a categoria criança da categoria infância. A primeira refere-se à dinâmica do desenvolvimento individual, particularizado, que eventualmente chegará à condição de adulto. A segunda localiza-se “(...) na dinâmica do desenvolvimento social e corresponde a uma estrutura permanente, embora se caracterize pelo fato de que os atores que a integram o fazem, transitoriamente, num processo de permanente substituição".

No Brasil, a dinâmica do desenvolvimento social requereu que a Constituição Federal de 1988, no contexto da doutrina da cidadania e da igualdade de todos, criasse um ordenamento jurídico, o ECA, que define criança e adolescência a partir da idade. Portanto criança refere-se a pessoas de até 12 anos e, adolescente, a pessoas acima de 12 e até 18 anos. Para a iniciação no mundo do trabalho, o ECA define a idade legal de 16 anos. E é considerando esse limite etário que a Lei 8.690 proibirá o trabalho infantil.

É importante destacar que as concepções de infância e adolescência, dentro da psicologia, também sofreram variações e assumiram diferentes contornos. De acordo com Ozella (2002), a concepção de adolescência na psicologia desenvolvimentista de caráter naturalista está fortemente ligada a estereótipos e estigmas. Considera o autor que tal fato se iniciou com Stanley Hall (1904), quando definiu a adolescência como uma etapa marcada por tormentos e conturbações vinculadas à sexualidade. Essa concepção foi reforçada por algumas abordagens psicanalíticas, que caracterizavam a adolescência como sendo marcada por confusões, estresse e lutos decorrentes dos impulsos sexuais.

Contrastando com essa concepção naturalista, partilha-se aqui da visão defendida por autores que, embasados na psicologia sócio-histórica, concebem a adolescência como um fenômeno histórico, dentro do qual determinadas necessidades sociais e todas as suas características foram desenvolvidas a partir das relações sociais com o mundo adulto e com as condições históricas em que se deu seu desenvolvimento (Bock \& Liebesny, 2003).

Como categorias estruturais, infância e adolescência interagem com outras estruturas, que afetam os processos de mudança da sociedade, sendo, por sua vez, afetados por eles. São construções sociais e históricas indicadoras do modo como diferentes sociedades organizam a reprodução de suas condições materiais e não-materiais de trabalho e de vida. Na sociedade brasileira, esse modo de ser é turvado pela necessidade de garantir-se a reprodução imediata da existência, induzindo crianças a assumirem responsabilidades adultas, em que a experiência do trabalho precoce se constitui em punição de sua condição social, ou seja, da classe social a que pertence (Adorno, 1993).

É importante lembrar que a legislação brasileira (ECA, Artigo 60; Emenda Constitucional no 20, de 16/12/1998) proíbe o trabalho para menores de 16 anos de idade, salvo na condição de aprendizes. A partir dos 16 anos, é permitido o trabalho com todas as garantias legais. Porém é vedado o trabalho em atividades insalubres e perigosas, e naquelas executadas no período noturno. Na época da realização desta pesquisa, a idade em que era permitida a inserção no trabalho doméstico era também a de 16 anos, sendo, por isso, a idade de referência legal que se adotou nas análises dos dados. É, no entanto, importante ressaltar que, posteriormente, o TID foi incluso na lista das piores formas de trabalho infantil, a partir do Decreto 6.481, de 12/06/2008, passando, então, a ser considerada atividade prejudicial à saúde, à segurança e à moral das crianças e adolescentes, podendo ser executada somente a partir dos 18 anos de idade.

Baseando-nos nesses fatores que permeiam o Trabalho Infantil Doméstico e na concepção legal de infância e adolescência presente nos documentos nacionais e internacionais sobre o tema, cabe-nos então discorrer sobre o conceito de Trabalho Infantil Doméstico, compreendido aqui como o conjunto das tarefas de cuidar da casa, de pessoas ou de animais, que podem ser realizadas para o próprio núcleo familiar ou para terceiros, sendo que, neste último caso, a remuneração pode ser feita em espécie ou em gêneros (Alberto et al., 2005). 
Alberto et al. (2005) identificam três modalidades de trabalho infantil doméstico: remunerado, ajuda e socialização.

- O TID remunerado é aquele em que o sujeito realiza o trabalho face ao recebimento de uma remuneração em espécie ou em gênero, ou seja, há uma relação de trabalho estabelecida. E a atividade de trabalho pode ser realizada em casa de terceiros, na própria casa da criança ou adolescente (realizando serviços de cuidar de crianças no próprio domicílio, por exemplo) ou em casa de parentes (tios, primos etc.);

- O segundo tipo, o TID ajuda, acontece quando crianças ou adolescentes assumem o conjunto das atividades de manutenção da casa, principalmente atividades indispensáveis à liberação de outros membros para o trabalho fora de casa, como cozinhar, cuidar de crianças, entre outros, podendo receber ou não remuneração por sua execução. Tais atividades podem ocorrer na própria casa ou na de parentes. Neste último caso, as relações de trabalho não são bem definidas e disfarçam relações de exploração entre eles, o que faz com que, nos casos em que há remuneração, esta seja ínfima;

- O TID socialização é aquele de acordo com o qual a atividade realizada decorre da divisão de tarefas entre os membros da família, sendo sempre realizadas na casa da criança ou do adolescente. Não existe remuneração e as tarefas demandam menos tempo de trabalho dos sujeitos do que os outros dois tipos de TID. São atividades que assumem o caráter de contribuição de crianças e adolescentes dentro da dinâmica familiar. Apesar de realizadas para a própria família, com caráter de contribuição, diversos autores (ver Heilborn, 2000; Rizzini \& Fonseca, 2002) encontraram em pesquisas que, mesmo nesses casos, a jornada de trabalho pode ocupar o tempo destinado aos estudos e ao lazer dessa população. Além disso, é frequente existirem casos em que as crianças sejam segregadas para o desempenho dessa atividade, o que contribui para a promoção e o aumento de sua baixa auto-estima e afetar a construção da identidade (Moreira \& Stengel, 2003; Santana \& Newman, 2001).

\section{Método}

Entre as abordagens utilizadas para a realização da presente investigação, utilizou-se a metodologia do diagnóstico rápido, que consiste no uso de um conjunto de instrumentos (técnicas quantitativas e qualitativas) com o objetivo de se conhecer e compreender uma determinada realidade em um contexto econômico e social particular, e de se atingir um número de sujeitos sem a utilização de amostragens científicas ou grupos de controle.

A metodologia do diagnóstico rápido tem sido desenvolvida pela OIT desde 2001, particularmente para investigar as piores formas de trabalho infantil, como é o caso do trabalho infantil doméstico, como complemento dos dados da Pesquisa Nacional de Amostragem Domiciliar (PNAD) do Instituto Brasileiro de Geografia e Estatística (IBGE) quando estes são insuficientes. Isso porque muitas dessas atividades são ilegais, invisíveis ou estão na informalidade, sendo de difícil identificação e pesquisa.

\section{Participantes}

Participaram desta pesquisa 100 sujeitos, de ambos os sexos, que estudavam em escolas públicas municipais e estaduais de João Pessoa, que se identificaram como trabalhadores e trabalhadoras domésticas. Esse número de sujeitos decorreu do critério de busca de participantes que estudavam em escolas com maior número de alunos, representativas nos bairros, ou em alunos participantes de programas de recuperação de aprendizagem. Porém, 
posteriormente, foi percebido que a maioria das crianças e dos adolescentes trabalhadores domésticos inseriam-se em escolas situadas em bairros que possuíam população de alto poder aquisitivo, que usufruía do trabalho desses sujeitos, o que fez com que fossem buscados participantes dessas escolas. Os sujeitos estavam inseridos tanto no Ensino Fundamental e no Ensino Médio, quanto em programas como o Acelera, Se Liga e Educação de Jovens e Adultos, sendo estes últimos programas destinados à recuperação da aprendizagem escolar.

Delimitou-se a faixa de idade dos participantes desta pesquisa entre os 7 e 18 anos de idade. A idade mínima de 7 anos foi considerada um critério porque, como a pesquisa seria nas escolas, essa era a idade mínima obrigatória exigida pela legislação brasileira para o início da escolarização. Quanto aos 18 anos, foi um critério seguido por ser essa a definição que a OIT usa para definir trabalho infantil (Organização Internacional do Trabalho, 2001). Os dados, no entanto, revelaram a existência do Trabalho Infantil Doméstico na faixa compreendida entre os 10 e 18 anos de idade.

\section{Local}

Escolheu-se o espaço escolar para a realização da pesquisa, uma vez que havia evidências anteriores (Alberto et al., 2005; Dantas, 2004; Rizini \& Fonseca, 2002) de que muitas das crianças e dos adolescentes inseridos no TID migravam para a capital não só em busca de trabalho, mas também de outros equipamentos institucionais, como escolas. Equipamentos esses que não existiam em seus locais de origem ou que funcionavam de forma precária. Além disso, ainda segundo outras pesquisas (Mendes, 2004; Sabóia, 2000), as meninas e os meninos inseridos no TID eram, entre os trabalhadores infantis, os que possuíam as maiores taxas de inserção escolar, mas as maiores taxas de defasagem série-idade.

\section{Instrumentos}

Foram utilizados dois instrumentos: o primeiro, denominado mosquito, consistia em um panfleto em que se perguntava a idade, a série e se o sujeito trabalhava, indicando a atividade. Seu objetivo era fazer um levantamento de quais crianças exerciam alguma forma de trabalho doméstico. Optou-se pelo mosquito como recurso de triagem porque evidências anteriores (Alberto et al., 2005; Dantas, 2004; Munich, 2003) identificaram que muitas meninas e meninos não queriam que os colegas soubessem que eram trabalhadores e trabalhadoras domésticos, pois tinham vergonha de exercer a atividade, devido ao preconceito social que a cerca. Daí a importância de não se esclarecer, na primeira abordagem, que a pesquisa era sobre o TID, mas apenas sobre trabalho infantil. Feita a triagem, voltava-se às salas e convidavam-se os meninos e as meninas identificados como trabalhadores e trabalhadoras domésticos para responder o segundo instrumento, o questionário. Nesse momento, fora da sala de aula, os meninos e meninas convidados eram informados de que se tratava de pesquisa sobre trabalho doméstico.

O segundo instrumento era um questionário composto por questões abertas e fechadas, englobando os seguintes aspectos: perfil sócio-demográfico, características da atividade, situação familiar, escolaridade, riscos. Este último instrumento permitiu uma análise tanto quantitativa, quanto qualitativa das respostas dos sujeitos. Ambos os instrumentos foram construídos pelo Núcleo de Pesquisa sobre o Desenvolvimento da Infância e Adolescência em Situação de Risco Pessoal e Social e utilizados em pesquisas feitas para a OIT (Alberto et al., 2005; Alberto, Wanderley, Souza \& Gomes, 2006a; Alberto, Silva, Santana, Vasconcelos \& Cirino, 2006 b). 


\section{Procedimentos}

Inicialmente, foram contatadas a Secretaria Municipal de Educação de João Pessoa e a Secretaria Estadual de Educação do Estado da Paraíba a fim de se obter a autorização para a realização da pesquisa nas escolas públicas. Em seguida, o projeto foi submetido à Comissão de Ética conforme a Resolução no 196 do Conselho Nacional de Saúde. Após a aprovação do projeto, partiu-se para as escolas.

Uma vez nas escolas, esclareciam-se os objetivos da pesquisa para os diretores e obtinha-se sua autorização para visitar as salas de aula, onde eram apresentados os pesquisadores, expostos os motivos da pesquisa, seus objetivos e convidavam-se os estudantes a participarem. Na ocasião, era assegurado o sigilo e aplicado o instrumento mosquito. A partir do mosquito, fazia-se a seleção daqueles sujeitos que declararam realizar trabalho doméstico. Retornava-se, então, às salas de aula e convidavam-se esses sujeitos a responderem ao questionário, que continha as questões abertas e fechadas.

\section{Análise dos dados}

Após o término da aplicação dos instrumentos, teve início a categorização das respostas às questões abertas, de acordo com a análise de conteúdo temática de Bardin (1994). Cada questão era lida, fazendo-se o recorte das unidades temáticas, o agrupamento e a categorização. Esse processo foi realizado por um grupo de pesquisadores que agiam mediante consenso, considerando para isso os referenciais teóricos utilizados e as etno-categorias. A próxima etapa consistiu na inserção das categorias no software SPSS. Em seguida, os dados passaram por outra revisão, na tentativa de se eliminar qualquer tipo de erro, inclusive de digitação. Após essa revisão, emitiram-se as frequências numéricas, as categorias semânticas, utilizando-se a estatística descritiva para tratamento e análise dos dados.

\section{Resultados}

Responderam ao instrumento mosquito 398 sujeitos de ambos os sexos. Destes, 54,28\% declararam que exerciam algum tipo de trabalho e 45,3\%, que não trabalhavam. Entre aqueles que trabalhavam, $29,15 \%$ o faziam em outras atividades e $25,13 \%$ exerciam trabalho doméstico. Estes últimos constituíram-se nos participantes desta pesquisa. Os inseridos no TID encontravam-se na faixa etária entre 10 a 18 anos, sendo $34 \%$ na faixa entre 10 a 14 anos e $25 \%$, entre 15 e 16 anos. A maior concentração deu-se em torno dos 17 e 18 anos, com $41 \%$ da população estudada.

A maioria, $73 \%$ da amostra, era do sexo feminino. No que diz respeito a raça/etnia, $67 \%$ definiram-se como afrodescendentes, aí compreendidos negros, mulatos, pardos e morenos. 30,0\% definiram-se como brancos e 3\% como amarelos.

Foram investigados também dados sobre a situação familiar dos participantes. Pôde-se verificar que as famílias são, em sua maioria, originárias de outros municípios (55\%), enquanto que $45 \%$ são de João Pessoa. Dentre os sujeitos originários de outros municípios e que migraram para João Pessoa, há aqueles que o fizeram juntamente com suas famílias e aqueles que migraram sozinhos. Dentre os motivos da migração familiar, os principais foram "busca de emprego" (69,2\%) e "busca de apoio familiar" (19,2\%). Quanto àqueles que migraram sozinhos, as principais causas reveladas foram "busca de oportunidades de emprego" (69\%) e "busca de melhores condições de vida" (13,8\%). 
No que se referia à quantidade de pessoas residentes por domicílio, $61,9 \%$ das famílias eram constituídas por 4 a 5 pessoas; $26,8 \%$ dos sujeitos procediam de famílias com 6 a 9 pessoas, e 11,3\% com 10 a 15 pessoas. A média, nesta pesquisa, ficou em 5,8 pessoas por domicílio.

Os dados revelaram que a renda per capita familiar variou de um quanto até um salário mínimo ${ }^{4}$, destacando-se a faixa de até um quarto do salário mínimo por pessoa da família, presente em $37 \%$ da amostra.

Constatou-se que um número significativo de famílias (86\%) participava de programas sociais, enquanto $14 \%$ não participavam de nenhum programa. Dentre os programas, destacouse o Fardamento e Livro, com $85 \%$, e o Programa Bolsa Família, com $68 \%$. É importante ressaltar que essa era uma questão de múltipla escolha, o que implica o fato de que, em muitos dos casos, a mesma família participava de mais de um programa de assistência. Assim, a maioria das famílias das crianças e dos adolescentes trabalhadores domésticos participava de algum programa, sendo que, no caso do Programa Bolsa Família, os valores recebidos já estão computados no cálculo da renda per capita familiar.

Quanto à atividade, 47\% da amostra constituíam-se de sujeitos que realizavam TID remunerado, 33\% que realizavam TID socialização e 20\%, o TID ajuda. Para a definição dessas modalidades, foram consideradas informações acerca de remuneração (em gênero ou espécie), horas de trabalho, local onde trabalhavam e tarefas que realizavam (ligadas ou não aos cuidados essenciais de manutenção familiar).

A inserção precoce no trabalho doméstico, no TID remunerado, ajuda ou socialização, deu-se na mais tenra idade: $2,1 \%$ começaram entre 5 e 6 anos; $62,9 \%$ começaram na faixa situada entre 7 e 14 anos; 25,8\% entre as idades de 15 e 16 anos; e 9,3\%, entre 17 e 18 anos.

Quanto aos motivos para a inserção no trabalho doméstico, destacaram-se as "necessidades financeiras", para 34,7\% dos sujeitos; as "necessidades da família", para 29,6\% (referem-se à necessidade, por parte da família, de que a criança ou o adolescente assumam as tarefas domésticas para que o restante de seus membros possa executar outras atividades); e a "rede de relações que oportuniza", para 24,5\%. Esta última categoria compreende os casos em que uma pessoa, que faz parte do círculo de relações da criança e adolescente e de sua família, a indica para o trabalho na casa de uma terceira, que necessita dos serviços de cuidado da casa e das pessoas (Alberto et al., 2005).

Na resposta à questão "para quem você trabalha", 50\% afirmaram trabalhar "para a sua família"; 36\% trabalhavam "para terceiros, na residência dos empregadores"; e 10\% "para parentes, na residência destes". Ainda 3\% trabalhavam "para terceiros, na residência do trabalhador ou da trabalhadora infantil" (por exemplo, cuidando de crianças de outras pessoas, porém fazendo isso na própria casa, ao invés de fazê-lo na casa dos empregadores) e 1\% "para parentes, na residência do trabalhador ou da trabalhadora infantil".

Entre os 50\% que trabalhavam para a família, 64\% eram TID socialização e 36\% TID ajuda. Já entre os 36\% que trabalhavam "para terceiros, na residência dos empregadores", 100\% eram TID remunerado. Por fim, entre os $10 \%$ que trabalhavam "para parentes na residência desses", 80\% eram TID remunerado e 20\% eram TID ajuda.

Quando questionados sobre as atividades que realizavam, obtiveram-se as seguintes respostas: $89 \%$, varriam casa, $85 \%$ colocavam lixo fora, $84 \%$ lavavam louça, $82 \%$ "passavam" pano no chão. $78 \%$ afirmaram que "faziam mandados", $76 \%$ disseram que lavavam banheiro, $75 \%$ acondicionavam lixo, $46 \%$ cozinhavam, 36\% cuidavam de criança sozinhos ou sozinhas, 17\% cuidavam de crianças com ajuda de alguém, e 13\% cuidavam de idosos. Estes últimos percentuais referem-se aos cuidados com pessoas. É importante destacar que a questão era de 
múltipla escolha, o que permitia que fossem indicadas todas as atividades executadas no trabalho pela criança ou pelo adolescente.

Verificou-se a renda mensal dos sujeitos que exerciam TID remunerado e recebiam em espécie pelo trabalho. Encontrou-se que 21,7\% recebiam de 1 a 10 reais, 30,4\% recebiam de 120 a 200 reais, e $47,8 \%$ recebiam de 250 a 380 reais. Na presente pesquisa, a média de salário auferido girou em torno dos $63 \%$ do salário mínimo. No que concernia à faixa de horas diárias de trabalho dos participantes, verificou-se que 43,4\% trabalhavam de 1 a 4 horas, 29,3\% de 5 a 8 horas e $27,3 \%$ de 9 a 15 horas. Pode-se perceber através dos dados que a maioria exerce pelo menos um turno de trabalho, o que já traz implicações para o exercício de outras atividades. É alarmante ainda o dado de $27,3 \%$ dos sujeitos trabalharem mais de 9 horas por dia, o que pode trazer graves implicações para o desenvolvimento global dessas crianças e adolescentes.

Foi perguntado aos adolescentes que exerciam TID remunerado se possuíam registro da atividade na Carteira de Trabalho e Previdência Social (CTPS). Desses, 97,9\% não tinham registro em carteira, enquanto apenas $2,1 \%$ responderam que tinham. Dentre os motivos para o não registro em carteira, destacaram-se questões ligadas aos patrões (não falavam, não queriam registrar os adolescentes ou não podiam pagar o salário mínimo) e ao fato de serem menores de idade. É necessário esclarecer que muitos dos sujeitos desconheciam que, na época da pesquisa, a partir dos 16 anos poderiam ter registro em carteira, de acordo com a legislação brasileira.

\section{Discussão}

É extremamente preocupante o dado de que mais de 50\% das crianças e dos adolescentes que responderam ao instrumento mosquito exerciam algum tipo de trabalho, o que revela o quão naturalizado é o trabalho infantil. Percebe-se também que mais de $25 \%$ deles exerciam trabalho infantil doméstico, o que demonstra que a sua execução não se configura enquanto caso isolado, mas como uma problemática que pode ter importância numérica ainda maior, em se considerando a amostra aqui pesquisada. Esses números evidenciam também a necessidade de maior quantidade de pesquisas nesta área, que permitam compreender melhor os fatores que contribuem para essa inserção precoce no trabalho.

Os dados referentes à idade corroboram os achados de Melo (2000) e de Sabóia (2000), que afirmam que, embora a maioria se encontre nas idades entre 17 e 18 anos, uma quantidade significativa de trabalhadores e trabalhadoras domésticas está na faixa etária compreendida entre 10 e 14 anos, idade em que a execução de trabalho é proibida.

Quanto à inserção no TID, a faixa etária de 7 a 14 anos coincide com o período no qual a criança começa a ter maior autonomia, tendendo, então, por isso, a perder os privilégios infantis dentro da família (Sarti, 1996). A partir dos 7 anos, é convocada a participar de alguma forma na manutenção do grupo familiar, adentrando então o mundo do trabalho, perdendo parte do tempo das brincadeiras, extremamente importante para o desenvolvimento cognitivo e afetivo. Além disso, é a faixa em que se inicia a escolarização, mostrando que, desde cedo, muitas crianças e adolescentes têm que lidar ao mesmo tempo com o trabalho e a escola, difícil conciliação que leva muitas vezes à repetência e à evasão escolar.

Esses dados confirmam os de outros autores (Alberto et al., 2005; Moreira \& Stengel, 2003; Sarti, 1996) de que a criança goza de determinados privilégios no seio da família, os quais são perdidos à medida que crescem e passam a ter condições de fazer algumas tarefas. O que significa que a infância, para as classes pobres, acaba mais cedo. É ainda digno de nota existirem crianças que começam a trabalhar entre 5 e 6 anos, fato que corrobora os dados de Sabóia (2000) e reforçam, ainda mais, a ideia da perda da infância ou mesmo a sua não- 
existência. Esse dado parece confirmar o que diz Pilotti (1995) quanto a categoria "infância" ser uma construção social e a categoria "criança" ser uma dimensão pessoal. Nem todas as crianças, portanto, vivenciam a infância.

O início da atividade de trabalho em idades entre 15 e 16 anos suscita a hipótese de que as escassas oportunidades de qualificação profissional fazem com que essas meninas e esses meninos sejam impelidos pela necessidade e pela falta de outras oportunidades a adentrar o mercado de trabalho informal, sujeitos a baixas remunerações e a longas jornadas (Rizzini \& Fonseca, 2002). Além disso, a insuficiência de equipamentos institucionais do Estado como, por exemplo, creches para as crianças, pode ser um fator contribuinte para que esses jovens sejam chamados a suprir a necessidade desse serviço nas localidades onde existe a demanda.

A prevalência de meninas corrobora pesquisas de diversos autores que abordam a temática (Alberto, 2002; Cervini \& Burger, 1991; Madeira, 1997; Mendes, 2004; Moreira \& Stengel, 2003; Munich, 2003; Tavares, 2002). Entretanto, mesmo com um percentual menor, porém significativo, verificou-se, em $27 \%$ da amostra, que os meninos também estavam realizando trabalho doméstico. Isso pode significar que eles estão se inserindo nas atividades domésticas por necessidade, ou que, no processo de socialização das famílias das classes populares, as crianças e os adolescentes são demandados para contribuir na divisão de tarefas, inclusive os meninos.

O índice predominantemente significativo de afrodescendentes realizando trabalho infanto-juvenil doméstico também corrobora pesquisas anteriores (Alberto et al., 2005; De Luca 2003; Freire, 1982; Kowarick, 1994; Mendes, 2004; Peres, 2002; Tavares, 2002) acerca da prevalência de crianças e adolescentes de descendência negra no trabalho infantil doméstico, particularmente no Nordeste brasileiro. Os dados obtidos na pesquisa, acerca desse predomínio, expõem as desigualdades que datam de muito tempo. A pouca ou nenhuma mobilidade social que vigorava na época da escravidão, no Brasil, somada à discriminação, acabou por manter o negro como ocupante dos serviços domésticos, aos quais, igualmente vistos de maneira discriminante, são atribuídos os menores salários. Ou seja, ser afrodescendente e pobre, na sociedade brasileira, parece definir socialmente quais as oportunidades e espaços de inserção social no trabalho e em outros aspectos da vida quotidiana, delineando cursos de vida marcados pela exclusão e pela dificuldade de ascensão social.

É extremamente significativo o fato de mais de 50\% dos entrevistados terem migrado para a capital do estado e de a predominância das causas desse deslocamento, seja ele pessoal ou familiar, referir-se à busca por emprego. De acordo com Alberto et al. (2005), outras pesquisas realizadas na área constataram que, entre as causas do trabalho infantil nas grandes cidades, a migração - e particularmente o êxodo rural - é um dos fatores determinantes (Haas, 2003; Kowarick, 1994; Moreira \& Targino, 1997). Rizzini e Fonseca (2002) apontam que era comum que meninas que moravam e trabalhavam nas lavouras da agricultura familiar buscassem o trabalho infantil doméstico como forma de conseguirem estudar e melhorar suas condições de vida, além de fugirem do pesado trabalho a que eram submetidas na agricultura familiar. Alberto et al. (2005) também constatam que as meninas trabalhadoras domésticas migram não apenas na busca de emprego, mas, aliado a isso, buscam equipamentos institucionais que não existem em suas cidade de origem, como escolas, por exemplo, que permitam ascensão sócio-econômica.

A faixa de residentes por domicílio mostra que a grande maioria das famílias integram de 4 a 5 pessoas, mas com um alto percentual de famílias com 6 a 9 pessoas também. Segundo dados do Instituto Brasileiro de Geografia e Estatística (2004), o número médio nacional de pessoas por domicílio, em 2003, era de 3,5 para a zona urbana e 3,9 para a zona rural. $\mathrm{Na}$ Paraíba, essa média era de 3,6 para a zona urbana e 4,1 para a zona rural. Já a média de pessoas por domicílio encontrada na presente pesquisa foi de 5,8 pessoas. Pode-se concluir, então, que, 
além de a média de pessoas por domicílio na Paraíba ser maior que a nacional, o que já implica desigualdades regionais, no caso das famílias com crianças e adolescentes trabalhadores, essa média tende a ser ainda maior, sugerindo que esse pode ser um fator contribuinte para a inserção precoce dos filhos no trabalho, que, aliado ao desemprego de adultos ou ausência de um dos genitores, faz com que as crianças e os adolescentes se insiram no trabalho em busca de promover algum aumento na renda familiar (Alberto, 2002; Heilborn, 2000), uma vez que as famílias dos participantes desta pesquisa eram compostas, em sua maioria, por membros crianças e adolescentes, e não por adultos.

No que concerne à renda per capita familiar, os dados encontrados são dignos de ênfase, frente à quantidade significativa de famílias constituídas por mais de 6 e até 15 pessoas, como também a predominância de uma renda de até um quarto do salário mínimo per capita. De acordo com Kassouf (2004), o Nordeste possui a menor renda domiciliar por pessoa do Brasil, que, em 2001, correspondia a $\mathrm{R} \$ 208,05$. A presente pesquisa, portanto, vem corroborar esse dado, salientando que os valores nela encontrados foram ainda mais baixos: em $37 \%$ dos casos, a renda por pessoa era de $\mathrm{R} \$ 87,50$ (um quarto do salário mínimo).

Sabóia (2000) indica que as meninas trabalhadoras domésticas são provenientes de famílias muito pobres. Segundo sua pesquisa, cerca de metade tem rendimento familiar per capita de até meio salário mínimo, resultado semelhante ao encontrado no presente estudo. A autora faz ainda um paralelo entre os rendimentos familiares das meninas trabalhadoras domésticas com os das meninas trabalhadoras de outras atividades e, ainda, com meninas que não trabalhavam. Os resultados indicaram que as rendas de meninas trabalhadoras domésticas e trabalhadoras em outras atividades eram semelhantes. Eram, no entanto, claramente inferiores quando comparados aos das famílias de meninas que não trabalhavam.

É importante lembrar que a maior parte dessas famílias ganha uma baixa renda mensal per capita de até um quarto do salário mínimo. O mais alarmante é que nesse cálculo já estão inclusos benefícios provindos de programas sociais dos quais as famílias participam (85\% participavam de algum programa), bem como a renda obtida no trabalho das crianças e dos adolescentes, no caso daqueles que exerciam TID remunerado. A partir desses dados, pode-se tirar duas conclusões: a primeira é que, mesmo com os rendimentos obtidos no trabalho doméstico, a renda per capita familiar continua extremamente baixa; a segunda é que os programas sociais não contribuem para uma efetiva elevação da renda familiar nem para a diminuição da indigência (Lavinas \& Barbosa, 2000). E, quando o fazem, não erradicam ou não impedem o trabalho infantil (Rua, 2007), como é o caso da integração do PETI com o Programa Bolsa Família. A integração eliminou os incentivos das famílias à retirada das crianças e dos adolescentes da situação do trabalho infantil, o que ocasionou perda do foco no trabalho infantil (Rua, 2007). As necessidades financeiras, que aparecem enquanto motivo para a inserção no TID, confirmam a influência da pobreza na entrada precoce no trabalho.

As necessidades familiares estão ligadas à disponibilização de uma ou mais crianças e adolescentes para assumir os cuidados da casa e a manutenção domiciliar a fim de que os outros membros tenham condições de sair para trabalhar. Ou seja, sujeitos ainda muito jovens precisam tomar para si todos os afazeres de uma casa, uma responsabilidade que geralmente é atribuída às filhas mais velhas, principalmente se os demais irmãos menores forem do sexo masculino (Heilborn, 2000). Assim, toma-se todo ou boa parte do tempo fora do espaço escolar e reduz-se o espaço para outras atividades, como os estudos e atividades de lazer e socialização. É essa uma das características comuns ao TID ajuda. Quanto ao motivo referente à rede de relações que oportuniza o trabalho, é uma prática comum nas camadas populares, que, aliada à necessidade financeira, submete os sujeitos a baixos salários e à exploração.

Entre as atividades que realizavam, percebe-se que a maioria executava atividades ligadas aos cuidados da casa. Em seguida, referiram-se a atividades ligadas ao cuidado com 
pessoas (cuidar de crianças, ensinar tarefas escolares), atribuições socialmente definidas como femininas, principalmente considerando-se que $73 \%$ são do sexo feminino.

Curioso observar também é que as atividades que aparecem com menores percentagens são aquelas realizadas no espaço externo, como cuidar de jardim, de cachorro, o que coincide com o que a literatura mostra, isto é, que essas atividades tendem a ser menos exercidas por meninas, já que a estas é reservado o espaço privado e a domesticidade (Heilborn, 2000; Rizzini $\&$ Fonseca, 2002; Tavares, 2002).

De acordo com as remunerações recebidas pelas crianças e pelos adolescentes, pode-se concluir que aqueles que exerciam TID remunerado constituíam um grupo que possuía relações de trabalho mais definidas, ainda que desiguais, e que recebiam, principalmente, em espécie por esse trabalho. Apesar disso, os valores recebidos estavam aquém dos valores pagos a um adulto, do que se conclui serem baixas remunerações. É importante ressaltar que as crianças e os adolescentes que exerciam o TID ajuda realizavam atividades que ocupavam um grande espaço de tempo, e que, de acordo com esta pesquisa, não recebiam remuneração em espécie (mesmo quando o trabalho era feito em casa de parentes), o que revela a característica de exploração da atividade. Possivelmente há, no mínimo, a cultura naturalizada de se explorar crianças e adolescentes no trabalho doméstico.

Como muitos patrões são familiares (já que uma característica do TID ajuda é o trabalho para parentes), outro traço cultural que também emerge é o costume de os parentes financeiramente mais abastados explorarem os mais desprovidos, trazendo-os de outras cidades para trabalharem e residirem em suas casas. Com relação ao TID socialização, ainda que as atividades se configurem como contribuição para a organização da família e assumam caráter de aprendizagem - e não necessariamente sejam prejudiciais -, é preocupante que essas crianças e adolescentes, como se pode perceber no conjunto dos dados sobre as faixas de horas de trabalho diário, exercessem pelo menos um turno de trabalho, o que já seria prejudicial em termos de tempo para lazer e estudos.

Os dados desta pesquisa, que objetivava caracterizar o TID em João Pessoa, revelaram que essa atividade era feita por crianças e adolescentes, nos tipos socialização, ajuda e remunerado. Embora haja nuanças, todos os três têm implicações, quer para crianças, quer para adolescentes. Isso já foi apontado por vários autores (Mendes, 2004; Moreira \& Stengel, 2003; Tavares, 2002) e pode ser confirmado nesta pesquisa ao se verificar que havia presença de todas as faixas de idade ao se analisar os seguintes aspectos: 2,1\% começaram a trabalhar entre 5 e 6 anos, 62,9\% começaram na faixa dos 7 a 14 anos. Nas faixas entre 5 e 15 horas de trabalho, estão mais de 56\% dos sujeitos. 59\% dessas crianças e adolescentes não brincam, principalmente, considerando-se que uma parte deles se encontra na faixa etária em torno dos 12 anos. 60,6\% identificam riscos sociais relacionados ao trabalho, afirmando que o mesmo não lhe "daria formação para o futuro" e provocaria "envelhecimento antes do tempo". De modo que não apenas as fases do desenvolvimento deveriam ser levadas em consideração, mas também as implicações relacionadas ao número de horas trabalhadas, a quantidade de turnos, as tarefas executadas, as relações de trabalho. Todavia, para efeito desta pesquisa, esse não era um objetivo e, portanto, não foi investigado, não podendo ser realizado agora porque os casos por idades não são uniformes (uma vez que foram tomadas sem a preocupação de obtenção de amostra científica, mas para se perceber como aparecem na realidade, como se configuram).

No caso dos dados sobre para quem esses participantes trabalhavam, observa-se um percentual alto de crianças e adolescentes realizando trabalhos domésticos na própria casa, para sua família, o que significa que, mesmo no próprio domicílio, essa é uma prática muito comum nas camadas populares, vista como forma de educação desses sujeitos (Heilborn, 2000; Rizzini $\&$ Fonseca, 2002), principalmente se for levado em consideração que parte exercia o TID ajuda como consequência da necessidade de suprir a falta de alguém para exercer a manutenção da casa, de forma a permitir que os demais membros possam trabalhar fora. 
Tem-se, ainda, que 36\% exerciam essas atividades em casa de terceiros, enquanto a maioria estava longe do convívio e da proteção familiar. Além disso, estavam expostos a longas jornadas de trabalho, baixa remuneração, assédio e abuso sexual e a todo tipo de violência. $O$ que agrava mais esse quadro é a dificuldade de fiscalização no espaço doméstico, já que o lar é considerado, pela Constituição Federal, espaço privado e inviolável. Por fim, a realização de trabalho doméstico "para parentes na casa desses" é ligada ao TID remunerado e ao TID ajuda, sendo que a relação de parentesco pode esconder a exploração do trabalho desses sujeitos, sob a alegação de que "é só uma ajuda", que desvaloriza o esforço dessas crianças e desses adolescentes, que são trabalhadores e que não são reconhecidos enquanto tais (Alberto et al., 2005).

Pode-se perceber que a maioria dos que exerciam TID remunerado recebia menos que um salário mínimo, ressaltando-se aqui que todos eram adolescentes. Nogueira (1993) afirma que o uso de crianças e adolescentes para o trabalho é uma forma de os patrões pagarem menores rendimentos, comparados aos de um trabalhador adulto, fato que aqui se confirma, segundo os resultados. Além disso, há um desrespeito ao que a Consolidação das Leis do Trabalho afirma - que nenhum trabalhador deve receber menos que o salário mínimo - no caso dos trabalhadores maiores de 16 anos.

No tocante aos dados sobre a jornada de trabalho diária, os dados apontaram que a maioria exercia cerca de um turno de trabalho, o que já traz prejuízos ao se considerar que isso irá afetar o tempo do brincar, de estudos complementares aos escolares, já que, no outro período, estão na escola. O fato de mais de $27 \%$ trabalharem pelo menos dois turnos é situação mais grave, o que mostra que praticamente não restava tempo para satisfazerem as necessidades supramencionadas. Dado estarrecedor é que meninos e meninas em processo de desenvolvimento intelectual, físico e afetivo exerçam 9 a 15 horas de trabalho, demonstrando que ocorria uma verdadeira perda da infância e adolescência frente à necessidade do trabalho.

A execução de atividades que exigem muito tempo e esforço físico dessas crianças e adolescentes, além de prejuízos no processo de escolarização (Alberto et al., 2005; Alberto et al., 2006a; Alberto et al., 2006b; Munich, 2003; Santana \& Almeida Filho, 1994; Santana \& Newman, 2001) e no direito ao lazer, pode causar riscos de problemas em seu desenvolvimento corporal, uma vez que se encontram em condição peculiar de desenvolvimento, conforme define o ECA. Ou seja, não estão preparados fisicamente para a execução de tantas atividades e de forma tão repetitiva.

\section{Considerações Finais}

Este estudo proporcionou fazer-se um rápido levantamento da existência e das condições do Trabalho Infantil Doméstico no município de João Pessoa. São dados que mostram quão oculta e perigosa pode ser a execução desse tipo de trabalho para as crianças e os adolescentes. Observe-se, ainda, que, apesar do pequeno número investigado, é possível que, considerada a totalidade de crianças e adolescentes com esse perfil, o quadro do exercício de tal atividade possa ser ainda mais grave.

Os participantes provinham, em sua maioria, de famílias muito pobres ou, ainda, daquelas que migraram em busca de emprego e de melhores condições de vida na capital, o que contribuiu para que tivessem de trabalhar a fim de ajudar no sustento familiar. Outros precisavam assumir todas as responsabilidades dos cuidados de uma casa e de pessoas para disponibilizar os adultos para o trabalho, deixando de ser sujeitos cuidados para serem sujeitos cuidadores. 
Uma parcela desses sujeitos migrou sozinha à procura de trabalho e pelo desejo de uma vida melhor, menos sofrida. Deixou, então, a família, as brincadeiras, o lazer, enfim, parte da adolescência para trabalhar e morar na casa de terceiros, expostos a todo tipo de riscos e de exploração. Outros ainda tinham a obrigação diária de realizar uma série de serviços que podiam, algumas vezes, tomar boa parte do seu tempo e até comprometer o acesso à escolarização.

A extensa jornada de trabalho que, para alguns sujeitos, prolongava-se até 15 horas diárias, juntamente com a maioria deles realizar trabalho doméstico ao longo de 6 a 7 dias por semana, faz crer que não restava quase nenhum tempo para o lazer, ou seja, para serem crianças e adolescentes. A não-garantia dos direitos para aqueles que já podiam trabalhar legalmente, principalmente no que concernia a salários e formalização do emprego, negava o seu reconhecimento enquanto trabalhadores e trabalhadoras; ainda que o dia-a-dia afirmasse o contrário, negava a cidadania.

O grande número de pessoas na família, a renda familiar per capita muito baixa, mesmo com os programas sociais e o rendimento dessas crianças e adolescentes trabalhadores domésticos, demonstram que é preciso mais do que programas sociais paliativos para se abordar o problema do trabalho infantil.

Por tudo o que foi exposto, pode-se concluir que o trabalho infantil doméstico constitui-se em uma violação aos direitos dessas crianças e adolescentes, no momento em que, muitas vezes, os privam do direito a ter infância e adolescência. Está intimamente ligado a questões como a pobreza, discriminações e exclusão social, mas também a uma cultura brasileira que pensa o trabalho, em especial o trabalho precoce, como antídoto contra a marginalidade.

Corroborando a ideia da infância e da adolescência como uma construção social demarcada pela ideologia de classes, encontraram-se, com esta pesquisa, crianças e adolescentes trabalhando, exatamente, na faixa proibida pelo ECA. O que pode significar que a instituição da Lei não é por si só suficiente para garantir a igualdade concebida na doutrina.

\section{Referências}

Abramo, L. (2004). Perspectiva de gênero e raça nas políticas públicas. Mercado de Trabalho: Conjuntura e Análise, $25(11), 17-21$.

Adorno, S. (1993). A experiência precoce da punição. In J. S. Martins (Org.). O massacre dos inocentes: a criança sem infância no Brasil. São Paulo: Hucitec.

Agência de Notícias dos Direitos da Infância (2005). Trabalho doméstico. Análise de Mídia: Piores Formas de Trabalho Infantil, 4, 29.

Alberto, M. F. P. (2002). A dimensão subjetiva do trabalho precoce em meninos e meninas em condição de rua em João Pessoa, PB. Tese de Doutorado, Programa de Pós-graduação em Sociologia, Universidade Federal de Pernambuco, Recife.

Alberto, M. F. P., Nunes, T. S., Cavalcante, C. P. \& Santos, D. P. (2005). O Trabalho Infantil Doméstico em João Pessoa, PB: um diagnóstico rápido à luz das piores formas de trabalho infantil. Brasília: OIT.

Alberto, M. F. P., Wanderley, J. C. V., Souza, G. P. \& Gomes, V. C. (2006a). Trabalho infantil na cultura do abacaxi no município de Santa Rita, PB: um diagnóstico rápido à luz das piores formas de trabalho infantil. Brasília: OIT.

Alberto, M. F. P., Silva, A. C. S. da, Santana, R. V. M., Vasconcelos, T. T. V. A. \& Cirino, D. C. S. (2006b). O trabalho infantil na atividade informal urbana em Guarabira, PB: um diagnóstico rápido à luz das piores formas de trabalho infantil. Brasília: OIT.

Ariès, P. (1981). História social da criança e da família. Rio de Janeiro: Guanabara.

Bardin, L. (1994). Análise de Conteúdo. Lisboa: Edições 70. 
Bock, A. M. B. \& Liebesny, B. (2003). Quem eu quero ser quando crescer: um estudo sobre o projeto de vida de jovens em São Paulo. In S. Ozella (Org.), Adolescência construída na visão da psicologia sócio-histórica. São Paulo: Cortez.

Cervini, R. \& Burger, F. (1991). O menino trabalhador no Brasil urbano dos anos 80. In A. Fausto \& R. Cervini (Orgs.), O trabalho e a rua: crianças e adolescentes no Brasil urbano dos anos 80 (pp. 17-46). São Paulo: Cortez.

Dantas, A. P. A. (2004). Trabalho infanto-juvenil doméstico como violação dos direitos humanos. Monografia, Graduação em Psicologia, Universidade Federal da Paraíba, João Pessoa.

Dejours, C. (1999). Homens, mulheres e suas relações de trabalho. In Conferências Brasileiras: identidade, reconhecimento e transgressão no trabalho. São Paulo: Fundap, EAESP/FGV.

De Luca, T. R. (2003). Direitos Sociais no Brasil. In J. Pinsky \& C. B. Pinsky (Orgs), História da cidadania. São Paulo: Contexto.

Freire, P. (1982). Educação como prática de liberdade. Rio de Janeiro: Paz e Terra.

Haas, F. (2003). O trabalho infantil doméstico nas cidades de Belém, Recife e Belo Horizonte: um diagnóstico rápido. Brasília: OIT.

Hall, G. S. (1904). Adolescence: its psychology and its relations to physiology, anthropology, sociology, sex, crime, religion, and education (vols. I e II). New York: Appleton.

Heilborn, M. L. (2000). Dimensões culturais do trabalho infantil feminino. Rio de Janeiro: OIT/ IPEA.

Hirata, H. S. (1998). Reestruturação produtiva, trabalho e relações de gênero. Revista Latino-americana de Estudos do Trabalho. São Paulo, 4 (7), 5-27.

Instituto Brasileiro de Geografia e Estatística (2002). Pesquisa Nacional por Amostragem de Domicílio - PNAD/2001. Rio de Janeiro: Autor.

Instituto Brasileiro de Geografia e Estatística (2004). Síntese de indicadores sociais 2004. Rio de Janeiro: IBGE.

Kassouf, A. L. (2004). O trabalho de crianças e adolescentes no Nordeste do Brasil. Brasília: OIT.

Kergoat, D. (1986). Por uma problemática do processo de trabalho doméstico. In A. Kartchevsky-Bulbort et al. (Orgs.), O sexo do trabalho (pp. 95-112). Rio de Janeiro: Paz e Terra.

Kowarick, L. (1994). Trabalho e vadiagem: a origem do trabalho livre no Brasil (2ª ed.). Rio de Janeiro: Paz e Terra.

Lavinas, L. \& Barbosa, M. L. de O. (2000). Combater a pobreza estimulando a frequência escolar: o estudo de caso do programa bolsa-escola do Recife. Dados, 43 (3), 447-477.

Madeira, F. R (org).(1997). Quem mandou nascer mulher? Estudos sobre crianças e adolescentes pobres no Brasil. Rio de Janeiro: Record/Rosa dos Ventos.

Marx, K. (1968). Trabalho, juventude e educação politécnica. In S. Britto (Org.), Sociologia da juventude I: da Europa de Marx à América Latina de hoje (pp. 15-18). Rio de Janeiro: Zahar.

Melo, H. P. (2000). Trabalhadoras domésticas: o eterno lugar do feminino. Uma análise dos grupos ocupacionais. Rio de Janeiro: OIT/IPEA.

Mendes, R. (2004). O Brasil sem trabalho infantil doméstico. In M. F. P. Alberto (Org.), Trabalho infanto-juvenil e direitos humanos (pp. 37-42). João Pessoa: Universitária/UFPB.

Moisés, J. (1982). Cidade, povo e poder. Rio de Janeiro: Paz e Terra.

Moreira, E. de R. \& Targino, I. (1997). Capítulo de geografia agrária da Paraíba. João Pessoa: Universitária/UFPB.

Moreira, M. I. \& Stengel, M. (Orgs.). (2003). Narrativas infanto-juvenis sobre o trabalho doméstico. Belo Horizonte: PUCMinas.

Munich, S. (2003). As condições e o sentido do trabalho doméstico realizado por adolescentes que residem no local de emprego. Dissertação de Mestrado, Departamento de Psicologia, Universidade Federal do Rio Grande do Norte, Natal.

Nogueira, M. A. (1993). Educação, saber e produção em Marx e Engels. São Paulo: Cortez.

Organização Internacional do Trabalho (2001). Combatendo o trabalho infantil: guia para educadores (vol. 2). Brasília: OIT/ IPEC.

Ozella, S. (2002). Adolescência: uma perspectiva crítica. In M. de L. J. Cotini, S. M. Koller \& M. N. dos S. Barros (Orgs), Adolescência e psicologia (pp. 16-24). Rio de Janeiro: Conselho Federal de Psicologia. 
Peres, A. (2002). Meninas domésticas. Maria Maria, 4 (4), 33-40.

Pilotti, F. (1995). A arte de governar crianças: a história das políticas sociais, da legislação e da assistência à infância no Brasil. Rio de Janeiro: Amais.

Rizzini, I. \& Fonseca, C. (2002). As meninas e o universo do trabalho doméstico no Brasil: aspectos históricos, culturais e tendências atuais. Rio de Janeiro: OIT/IPEC.

Rua, M. G. (2007). Avaliação da integração do programa de erradicação do trabalho infantil (PETI) ao programa bolsafamília (PBF). Brasília: Fórum Nacional de Prevenção e Erradicação do Trabalho Infantil/Organização Internacional do Trabalho.

Sabóia, A. L. (2000). As meninas empregadas domésticas: uma caracterização socioeconômica. Rio de Janeiro: IPEA/OIT.

Santana, V. S. \& Almeida Filho, N. (1994). O emprego doméstico e o sofrimento mental. Saúde Mental em Revista, 2, 9-28.

Santana, V. S., Loomis, D. P. \& Newman, B. (2001). Trabalho doméstico, trabalho assalariado e sintomas psiquiátricos. Revista de Saúde Pública, 35 (1), 145-150.

Sarti, C. A. (1996). A família como espelho: um estudo sobre a moral dos pobres. Campinas: Autores Associados.

Tavares, M. A. (2002). Onde está Kelly? O trabalho oculto de crianças e adolescentes exploradas nos serviços domésticos na cidade do Recife. Recife: CENDHEC.

Whitaker, D. C. A. (2002). Nas franjas do rural-urbano: meninas entre a tradição e a modernidade. Cadernos Cedes, 56, (4), 7-22.

\section{Endereço para correspondência}

jfalberto@uol.com.br,denyps@yahoo.com.br

Recebido em: 10/06/2008

Revisado em: 20/10/2008

Aprovado em: 21/10/2008 